Mariela Nuñez-Janes and David Oliveira Franco, Jr. 7 lamWe: Digital Storytelling, Personal Journeys, and Praxis ${ }^{17}$

\title{
7.1 Introduction
}

In 2007 a college professor and a high school teacher began to forge connections between their high school and university by giving high school youth the opportunity to share their stories through digital storytelling. They developed a program named IamWe by the high-school youth who participated in a digital storytelling workshop. IamWe became part of a Texas high school PALs (Peer Assistance Leadership) class. Through this program over 100 high school students produced their own digital stories and developed Participatory Action Research (PAR) projects about their school and community.

In this chapter, we discuss the practice of digital storytelling as it relates to personal growth among high school youth who were part of the IamWe program. Our discussion draws on data collected for an assessment conducted during the 2010-2011 academic year, although examples are also drawn from observations and interviews gathered throughout a nine-year period. We analyze digital storytelling and contribute to scholarly discussions that emphasize the pedagogical opportunities that digital storytelling offers to integrate technology and meaningful learning activities in classroom settings (Heo, 2009; Kajder, 2004; Miller, 2010).

In the IamWe program the effectiveness of digital storytelling was integral to the process of creating a digital story - a series of activities that helped youth construct meaning and facilitate multiple border crossings or "personal journeys" that encouraged trust and empathy among the youth. As the high school youth participated in trust building activities, a story circle, and the process of digitizing their stories, they found commonalities and differences between their lives and the lives of their classmates. The activities fostered what we theorize as dialogical encounters or pedagogical opportunities for reflections and actions that helped the high school youth listen and share diverse experiences with the assistance of media technology.

17 We want to acknowledge Mr. Tim Sanchez (PALs advisor), Will Richey, and Alejandro Perez for their commitment to IamWe and their willingness to share their knowledge and talent over the years. Felipe Vargas introduced us to Campecine and his vision has been an inspiration. We are thankful to all of the University of North Texas students who were part of IamWe as mentors or volunteers in particular: Kimberly Davis, Nancy Gillis, Micaela Kline, Sara Masetti, Amy Zapien, Preston LaFarge, Nydia Sanchez, and Kaleb Hadenfeldt. We are also indebted to all the PALs for sharing their stories with us. 


\subsection{Putting Ideas to Practice: Theoretical Foundations}

Many technology tools and techniques aimed at transforming teaching and learning are available for students and teachers. As a digital tool, digital storytelling has been used for a multitude of purposes including: community-based participatory research (Gubrium, 2009), alternative forms of literacy (Kajder, 2004; Miller, 2010), increasing teacher disposition towards technology integration (Heo, 2009), incorporating and legitimizing student knowledge in the classroom environment (Nuñez-Janes, 2009), new media literacy and IT skills (Sadik, 2008), and fostering moral values (Mukti \& Hwa, 2004). Further, the use of this tool has also expanded from K-12 into higher education (McLellan, 2006).

Several methods and techniques are involved in the process of creating a digital story. These methods are considered the "... art and craft of exploring different media and software applications to communicate stories in new and powerful ways...” (McLellan, 2006, p. 66). The key to successful technology integration through digital storytelling is related to authentic, meaningful, and captivating learning activities rather than the actual use of hardware and software. Fundamentally, according to Sheneman (2010), digital storytelling incorporates these traits, and targets a generation that has the “... ability to weave together images, text and sound in a natural way” (p. 40).

We relied on the concept of digital storytelling praxis-"the use of media technology and stories to reflect (research) and change (act upon) the educational lives of [] students” (Nuñez-Janes \& Re Cruz 2013) and introduce in this chapter the idea of dialogic encounters to theorize the opportunities that digital storytelling offers to foster authentic and meaningful connections between media technology and the lived experiences of high school youth. Narratives are embedded within stories, which are strung together through words, actions, thoughts, and in this particular case through digital media (Ochs, 2007). As stories were shared in the IamWe program through digital media, youth learned about their peers' past, their thoughts about the future, and their perspectives on a variety of topics. In this process, the practice of digital storytelling helped youth work against distrust and prejudicial judgment towards their peers.

IamWe relied on youth's existing familiarity with digital media to tell their stories (Gubrium, 2009; Kajder, 2004; Nuñez-Janes, 2009; Robin, 2008; Skouge \& Rao, 2002). The curriculum for IamWe was developed as a result of a pilot study involving a threeday workshop conducted by the Center for Digital Storytelling (CDS) in 2006. CDS's, now StoryCenter's, emphasis on the story circle as shared dialogued was a key element of the IamWe program.

The IamWe curriculum was developed based on a series of theories related to pedagogy, social phenomenon, and research which were applied by integrating technology to the process of creating digital stories. With respect to pedagogy, IamWe was informed by the following theories: Latina/Chicana Feminist Pedagogy, a synthesis of every-day forms of teaching, learning, and community transformation (Delgado, Elenes, Godinez, \& Villenas, 2006), and Critical Praxis, a dialogic practice of education 
for freedom (Freire, 2000/1968). Specifically, the curriculum was built around Latino/a cultural values such as conversación (dialogue) and convivencia (collective teaching and learning) practiced as culturally relevant educational tools with an ethnically diverse group of youth. These values were implemented through the use of media technology, storytelling, and action research. With respect to research, IamWe was informed by Participatory Action Research (PAR) and Youth Participatory Action Research (YPAR)-a research process in which youth act as researchers and engage in community action (Cammarota, 2008; Fals Borda \& Rahman, 1991). Finally, with respect to social phenomenon, the idea of cultural wealth was also used as a framework. Cultural wealth, defined as accumulated assets and resources of marginalized communities that include different types of capital (aspirational, familial, social, linguistic, resistant, and navigational), guided the practice of storytelling (Yosso, 2006).

To this extent and based on these theories, the dialogue and communication created through a digital storytelling praxis resulted in what Paulo Freire called "element critic pedagogic," which is simultaneously creative and liberating. In this case youth were able to integrate their personal experiences or "personal journeys" to the learning process relevant to the PALs classroom. The activities that were part of the curriculum were primarily centered on dialogue and communication to engage youth in a dialogical process-a personal journey that involved themselves and others. A connection between digital media and personal narratives assisted the teacher and high school youth to "overcome some of the obstacles to productively using technology in the classroom” (Robin, 2008, p. 222) and improve the youth's attitudes towards each other. The activities that were part of IamWe were directed towards building bonds of trust and respect.

\subsection{The IamWe Program}

The program blended oral history, digital technologies, and culturally relevant pedagogies (Benmayor, 2000) to integrate "funds of knowledge" (Moll, 1992; Olmedo, 1997) into schooling. Some of the high school youth that participated in the initial pilot study "could not wait" to do more digital stories. This urgency launched a group effort between the PALs ${ }^{18}$ advisor and the Anthropology department at the University of North Texas (UNT).

18 Part of a nationwide initiative, PALs strives to build tomorrow's leaders through peer assistance, peer helping, and leadership. It is an extra-curricular program, adopted as an accredited elective course by the Texas Education Agency reaching over 750 Texas school districts and over 1000 schools in the U.S. Based on recognizing youth's potential to effect change and make a difference in their schools and communities, the PALs curriculum focuses on teaching students skills such as group dynamics, self-esteem, and problem solving, while developing cultural awareness ("Peer Assistance and Leadership," 2014). 
In 2008 the IamWe curriculum was revised to further facilitate the goals of PALs, particularly the need to create a service oriented, diverse, and empowered group of young leaders ready to build relationships between students and tear down the boundaries between diverse groups within the school. New activities were included and others were revised to prepare the high school youth for a diverse college environment. These activities emphasized personal growth and were designed to affect the youths' attitudes towards higher education while creating skills for college readiness. They focused on instilling in youth what one of the program collaborators, Will Richey, calls the "emotional literacy" necessary to navigate diversity. The idea was to assist students to better understand their peers. The curriculum revolved around three main activities: 1) a digital storytelling workshop, 2) participatory action research projects, and 3) an interactive film festival (Campecine). These activities were carried out in sequence during the academic school year.

The week prior to the digital storytelling workshop, PALs students met in a portable classroom in the back of the school's campus. A setting outside of the school building was chosen to help the youth share their experiences more freely. The story circle was designed to help students share stories with their peers and brainstorm which story they would choose to develop into a digital story. The story circle was often considered a highlight of the program by many of the youth, even when they found it difficult, surprising, and emotional. In addition, as the "heart" (Lambert, 2013) of the digital storytelling process the story circle helped participants find their story by sharing and listening to personal narratives. In the story circle the youths' life experiences were at the center of dialogue while youth "...lead with the authority of their own lives" (Lambert, 2013, p. 76). The circle was facilitated by the PALs teacher, and the participants included high school youth, the researchers, and college student volunteers.

The story circle began with questions used as prompts to foster reflection and dialogue among the youth. The questions included, "What was the happiest moment in your life?" "Can you share something about you that others don't know?" The majority of the youth talked about time spent with their families or friends and shared personal, emotional, funny, sad, traumatic, or joyful experiences. Many youth cried during the story circle and others hugged each other seeking comfort. This activity lasted for the entire period of the class, over an hour, and in some cases half a day. On the following days, the youth wrote their stories and created storyboards to begin planning their digital story.

The weekend long digital storytelling workshop and Campecine film festival took place at UNT. It was an opportunity for youth and their families to experience a college environment sometimes for the first time. Students spent three days digitizing their stories. This included recording voice over narrations, inserting photographs, video, and sound, editing, and sharing their digital stories for the first time with other PALs and family members in a celebration. 


\subsection{Context and Methods}

Oscar Lewis High School ${ }^{19}$, is part of the Oscar Lewis Independent School District founded in 1882. Accredited as one of 50 international baccalaureate schools in Texas, it serves 9 th through 12 th grades. It was ranked academically acceptable by the Texas Education Agency (TEA) in 2011, a rating it has maintained since 2006. In 2012, according to TEA, the district served 24, 738 students, 52\% identified as white, 31\% Hispanic, and 12\% African American; 43.2\% qualified as economically disadvantaged. One of three high schools in the district, Oscar Lewis High School serves over 1,500 students. The school's racial and ethnic student composition roughly mirrors that of the district: 47\% white, 32\% Hispanic, $17 \%$ African American, and 43.9\% economically disadvantaged, a growing number. The percent of graduating students taking advanced courses at the high school, and considered college ready, is declining, while this percentage is increasing within the district.

Enrollment and participation in the PALs class occurs through a selection process. The process accesses a series of student characteristics and is led by PALs students from the previous academic year. It is done in two phases. Students from the previous year nominate other non-participating students based on their informal assessment of their leadership skills, maturity, and school involvement. Before the nomination, the prospective students fill out an application form. This application form provides the selection committee with a student profile that includes detailed information about their demographics, school year schedule, grades, school activities, interests, perceptions about the community, and thoughts about leadership, along with details about their personalities, life goals, and priorities. Once applications are collected and analyzed, students from the previous year's cohort vote on their preferred candidates. The process of voting is entirely anonymous. Once the candidates are selected, the PALs sponsor goes through the list of selected candidates and makes adjustments if deemed necessary. The program initiates its activities with a summer training that covers PALs, peer mentoring, and mediation.

The 2010-2011 PALs class was comprised of 28 students although in other years there were up to 35 juniors and seniors with ages ranging from 16- to 18-yearsold. Ethnically, the composition for the 2010-2011 academic year was diverse, 29\% Latinos/Hispanics, 25\% African-Americans/Black, 25\% white/Caucasian, 8\% white/Hispanic, 4\% Filipino, Albanian, and other. This demographic composition reflected the high school's overall ethnically diverse population.

Most of the data discussed in this chapter was collected between August 2010 and January 2011 as part of David Franco's Master's Practicum project in applied

19 The names of the school and high school youth are pseudonyms. 
anthropology. Of the total population, 25 students answered a pre and post leadership skills assessment survey (Ellis, 1990), 22 students participated in initial semi-structured interviews, and 19 students participated in final semi-structured interviews. This chapter is also informed by seven years of collaboration with the PALs program during which youth produced over 125 digital stories http://www. youtube.com/user/DHSPALS/videos? view=0\&sort=da\&flow=grid and nine videos about their PAR projects.

The research questions that guided the 2010-2011 study were:

1. How does IamWe affect student participants' attitudes towards higher education?

2. How does the IamWe program prepare students to enter college?

3. How does the digital storytelling praxis implemented in IamWe, particularly the use of media and culturally relevant activities, affect students' personal growth?

4. In what ways and to what extent does the PAR component of IamWe effectively help promote students' leadership?

This chapter will focus on the findings relevant to question three.

Classroom ethnography was the main tool of data collection. This ethnography pays attention to "the covert, tacit or implicit cultural patterns that affect behavior and communication particularly in face-to-face social interaction, and that are largely outside the consciousness of the actor" (Spindler \& Spindler, 1997, p. 60). Classroom ethnography elicits the youths' point of view and critical reflection of the cultural reality of the school and classroom. Data was collected through formal and informal interviews conducted before and after the completion of the IamWe program, surveys, and participant observation. The main focus was on the use of media and culturally relevant activities, as it related to students' personal growth and attitudes towards higher education. As participant observers, both of the authors actively participated as program facilitators with the assistance of college students, while the high school youth acted as researchers in their respective PAR projects.

The analytic practices used in this project draw from grounded theory (Glaser \& Strauss, 1967). We continuously read through observation notes, rearranged codes, isolated themes that were predominant, and identified themes related to context, student interaction, and the implementation of IamWe. Themes included higher education as an envisioned goal, necessary, natural, and positive, preparing for college by recognizing that everyone has a story, realizing personal lessons through trust, and learning to be less judgmental. Memoing was used to assist in relating the data to the scholarly literature (Bernard, 2006, p. 492). 


\title{
7.5 Findings and Discussion
}

\subsubsection{Trust}

\begin{abstract}
"My loved ones, my friends, my family, my teachers, I am sorry if I ever pushed you so far that it hurt. You loved me regardless. My loved ones, who would have given up their sanity to make me feel whole because they saw me in pieces. I broke down in the arms of my mentors, fell apart in the classroom of my instructors, and ran so far when I saw their arms reach out to help me. Never let me go!"-Maria
\end{abstract}

In her digital story Maria tells her story of recovery from trauma. Her story begins with her realization of recovery as a lonely journey. We see a black screen and only hear her voice as she admits, "I have to survive this!" Images of family and friends flash as she tells us about the trauma she experienced. "Because at the age of 16 I defy in silence!" is how Maria described the initial way she coped with the trauma she experienced. We then see images of family, teachers, and friends as Maria story unfolds from loneliness into her expression of her need for love and support, her cry to "Never let me go!" and her knowledge that "These people gave me butterflies in my stomach when I first felt that I was no longer alone.” Through Maria's digital story we witness her personal journey of transformation from solitude to accompaniment, decline to recovery. While many factors outside of the IamWe program contributed to Maria's recovery, digital storytelling allowed Maria to share her journey by expressing through words, images, and sounds the complex emotions she felt during her road to recovery. Maria relied on her love for poetry and photography to communicate her experience and she was inspired by the trust she felt in her peers to share a story that most of them were not aware of.

Youth like Maria felt compelled to share very personal stories and felt that IamWe helped them to trust their peers. Learning to trust other PALs occurred in the context of the story circle and in relation to several trust building exercises designed to build rapport among the youth. The emphasis on sharing personal experiences in the story circle was critical to fostering trust among the high school youth. When asked about the process of digital storytelling, Tabatha said that her initial perceptions were that this activity was "sketchy." Tabatha's initial reaction towards the story circle was "I don't like it. I had just met these people I had only known for a couple of months barely and I was scared."

Despite this initial fear, Tabatha felt that the story circle helped her change her perspective. She told us "I think it [story circle] specifically helped me because I had to force myself to go out of my way to share something about myself and then listen to someone else about themselves." By the end of the story circle Tabatha's initial apprehensions changed. The people she initially characterized as strangers were now worthy of her trust. After sharing a very emotional and personal story with her peers during the story circle she felt that "It is a story I trust to tell PALs, but it's 
not something I would tell the general public.” Similarly, Christen told us that she surprised herself during the process of creating her digital story because, as she put it, "I was really nervous to do it in first place but I was surprised on how much I trusted everyone in PALs and how trusting PALs can be. That is just not the norm in today's society to be trusting to anyone. That is how I was surprised."

For many youth, trust-building exercises practiced in the days prior to the story circle helped forge personal connections with other youth and prepare them for the emotions of the story circle. For example one youth explained that the trust building activities “...help[ed] a lot because it is hard to trust people you don't know.” The combination of the story circle and trust building activities helped build trust among the youth and foster comradery. For Susan the best part of doing digital storytelling was uniting the PALs class. She explained that she experienced this group unity in the form of "...having a greater connection, friendship and trust."

As Delgado Gaitan (2005) suggests, the use of stories, in particular sharing stories, builds connections and trust. For Delgado Gaitan (2005) "community action and social change have roots in personal family narratives that connect members within the same household, between families and schools, and between families across national borders"(p. 265). In the same way, the practice of digital storytelling through the integration of pedagogy, storytelling, and media technology, helped foster trust among the youth who participated in the IamWe program. This combination was transformative for the youth helping them cross barriers that kept them from connecting to each other. Delgado Gaitan (2005) explains the transformative quality of integrating storytelling and media technology in the following way,

"Yes, computer literacy is critical in accelerating communication. But the important lesson I glean from the families in these communities is that while our personal narratives may seem like small stories, small stories can be huge. They are a part of a longer narrative of survival, of wars in distant homelands, of isolation, of illness, of poverty, and of courage. In these people's stories, the recurring theme is about confronting and transcending the fear of not knowing and using personal stories to preserve the thread that defines us.” (p. 271)

\subsubsection{Being Less Judgmental}

"Hate, intolerance, isolation, hostility, revulsion, disgust, contempt, discrimination...so what is it that stops people hating? And how can we stop it? For me it was personal experience"-Carla

Carla's digital story was about challenging discrimination through personal experience. As we see images of demonstrators holding signs that say "Fags are beasts," "God hates you," "All gays go to hell," we hear Carla ask how homophobia can be stopped. She tells the story of a happy nuclear family that ended in divorce 
and we see pictures of her as a young child. She describes her parents' divorce as the end of her "innocence and ignorance." When her mom told her that she is gay Carla wondered how her mother would be able to endure the discrimination and hate towards people like her. Carla tells us in her digital story that she realized that her parents' divorce “...gave [her] more opportunities to receive love.” As we hear this important lesson we see photographs of Carla's new extended family. Carla's personal journey into the love of a new family, as she shared it in her digital story, “...taught me how much the world can hate and how much I can love." Carla shared a deeply personal journey with ramifications for understanding and transforming social issues rooted in discrimination, racism, sexism, and homophobia. Carla expressed the implications of her personal story through a photograph of the New York City Twin Towers prior to the 9/11 terrorist attacks shown as the last image of her digital story.

As in Carla's case many youth were surprised to learn about each other's experiences. Learning about their peers' stories facilitated the youth's awareness of other points of view and helped situate their judgments in the experiences of youth they learned to trust. Maria said that her judgment towards others changed after participating in the program. As she put it, “I don't think I've been antisocial, but I think I am more social now and not so hard on some people. You never know what people have gone through since you don't know their story and so I guess I just don't judge people as much as I used to.” Sue explained the lessons she learned about empathy as changes she saw in herself, as she put it, "I've become more accepting. I am, I guess, more understanding towards others and myself." Others students, like Camila, identified the digital storytelling process and, particularly the story circle, as a pivotal moment,

"The storytelling, the digital storytelling, but not the digital storytelling itself but whenever we were brain storming for it...when we were in preparation for it and playing around the world in the portable. I really got to see other people's views and see how other people were like and it made me extend my view on some of my opinions."

Similarly for Martha, the digital storytelling process, allowed her to connect her experiences with the experiences of other students,

"Basically, when I was able to share my story it helped me because I like helping people and stuff. Other people can understand that they are not alone and that they are not the only ones to go through stuff. They have a connection and they have somebody they can lean on.”

The opportunities to share their personal stories through the use of digital media contributed to what the youth envisioned as their personal growth. Closely aligned with the literature on digital storytelling and with previous research in this particular area (Gubrium, 2009; Kajder, 2004; Nuñez-Janes, 2009; Robin, 2008; Skouge \& Rao, 2002), IamWe facilitated opportunities for youth to use digital media, an important 
and intimate portion of their daily lives (Robin, 2008), to share their stories and find in their experiences relevant sources of knowledge. In a school environment and outside the boundaries of a set classroom assignment, youth rarely have an opportunity to share their stories. Through the process of creating their digital stories youth learned about commonalities and differences between their lives and the lives of their peers.

\subsubsection{Personal Journeys and Praxis}

The youth that participated in the IamWe program often described it as a "personal journey." As a deeply personal process, the practice of digital storytelling in the IamWe program involved the combination of several dialogic encounters. That is, conversations involving youth, media, written, and oral stories, images, sound that came together in the digital story itself and that we theorize as the pedagogical praxis of the digital storytelling process. These dialogic encounters relied on media technology and storytelling, involved emotions, and served pedagogical purposes. Indeed, the emotions involved in the process of creating digital stories were hard for the youth to put into words because, as many told us, they were meant to be experienced. Yes, digital stories can be described through the sum of their parts and through the steps involved in making them, but the deep effects of digital storytelling were crystallized in its process and conveyed in its final product. For example, in addition to the emotional content of the story circle youth experienced a multitude of emotions during the weekend long workshop. The emotions varied but included frustration with the technology, exhaustion, and a sense of accomplishment.

The depth of emotions shared during the story circle and permeating the entire process was surprising to many of the youth. Many felt that they were not "prepared" for what they described as the "somber tone" of the circle. One youth described the emotional content of the story circle in the following way, "I mean you are dealing with stuff, like your story is just; your story is about something that brings tears." Yet, despite the difficulties, many youth found the emotional quality to be the most compelling part of the process. The lessons they learned, "never count anybody out," "not to like judge anybody," and "that we could get it all done," had the effect of helping the PALs class "bond" and feel a sense of empathy towards other youth in the group. As one youth told us, “...in the end and stuff it's more easy to care about them [other youth]."

As a personal journey, the dialogic encounters of the digital storytelling process included: 1) conversation, 2) voice and narrative, 3) collective engagement, and 4) media. The conversational aspect of digital storytelling was most evident during the story circle. Several educational scholars and anthropologists discuss dialogue in relation to pedagogy and praxis. According to Freire (2000/1968) open dialogue is creative and liberatory. As a critical element of pedagogical praxis, Freire 
conceptualized dialogue as exchanges based on respect and cooperation that lead to just actions.

The digital storytelling journey continued by engaging the voices of youth as "counterstories” or "counternarratives," “...a method of recounting the experiences and perspectives of racially and socially marginalized people” (Yosso, 2006, p. 10), to challenge: 1) the use of power to privilege some stories over others, 2) the knowledge produced through stories, and 3) the privilege given to those who are allowed to tell stories (Knight, Norton, \& Dixon, 2004; Yosso, 2006). This dialogic encounter with voice is related to the praxis of conscientization that is part of the digital storytelling process. Freire discussed consciousness raising as an important aspect of transforming social reality. In this case the digital stories created by the youth were about raising the consciousness of the group about individual experiences related to absent fathers, drug addiction, alcohol abuse, mothers and grandmothers as mentors and role models, rape, the impact of family, and the love between siblings and friends.

Collective engagement was also an important element of the IamWe digital storytelling process. Feminist scholars have discussed collectivity and community as key elements of praxis. Black feminist anthropologists theorize praxis as situated in collective memories and as a point of departure for theorization, research, and activism (McClaurin, 2001). Chicana/Latina feminist ethnographers also situate praxis in collective experiences (Delgado, Elenes, Godinez, \& Villenas, 2006). In digital storytelling, stories are shared and produced in a group setting generating a collective sense of self and giving authority to the ways of knowing of youth. Another dialogic encounter involves transformation. Transformation occurred by involving youth, as the PALs teacher put it, "as a whole person," integrating emotion, voice, and media through the practice of digital storytelling. In the case of IamWe digital storytelling facilitated opportunities for youth to share their individual hardships and triumphs, "Perhaps not in point by point experiences," as the PALs adviser explained, but in the commonality of the struggle of coming to terms with becoming adults and the difficulties of "facing their biggest fears head-on."

\subsection{Conclusion and Implications}

The digital storytelling process practiced through the IamWe program contributed to facilitate high school youth's personal growth. Through a series of dialogic encounters involving conversations, voice and narrative, collective engagement, and media youth were able to learn about trust and empathy as they participated in trust building exercises, a story circle, and a digital storytelling workshop. These dialogic encounters allowed the youth to venture into emotional spaces, crossing personal boundaries, through a deeply personal journey converging in the digital story.

Yet, for the youth who were part of IamWe one of the most difficult aspects of digital storytelling was the vulnerability that permeated the process and that was 
most prevalent during the story circle. Youth described the story circle as "awkward" and told us during a group discussion how difficult it was to "open up" and to figure out "how much to tell" during the circle. Sustaining this heightened level of emotion through the whole process was difficult.

Despite the difficulties, most of the youth involved told us that what they liked the most about digital storytelling was also hearing their peers' stories, experiencing their digital stories, and sharing their emotions with each other. Thus, they described the effect of the story circle as helping them "get closer" and build trust. From the process of making a digital story they learned not to "count anybody out" or to "judge." They also felt that getting to know each other and actually finishing the whole process"getting it done"-helped them feel a sense of accomplishment.

We expanded the lessons gained from youth's personal journeys beyond the PALs classroom into a community film festival. In collaboration with Firme and Felipe Vargas we incorporated the Campecine film festival as an end point to the annual activities that were part of IamWe. This public event drew on the principles of conversation, voice, collective, engagement, and media. It featured some of the youth's digital stories and trust building activities led by the PALs. The emotions of the IamWe process were underscored by the performances of Will Richey and Alejandro Perez, a team of spoken word artists, experts in building emotional literacy with youth. Campecine brought together college students, professors, parents, teachers, and administrators under the leadership of the high school youth. This event was described as "life changing" by the youth and the rest of the participants.

The transformative or life changing impact of the digital storytelling process also had an effect on our own teaching practices and ideas about applying anthropology. First, as educators, we became more attentive to the voices of our own students and we are constantly working on developing strategies to incorporating their experiences as relevant sources of knowledge in our classrooms. Second, in our own collaboration, we became more attentive to our standpoints as well as those of our partners. Wolf (1996) suggests that researchers must accept existing power differentials in the research process. Our commitment to creating more egalitarian research relationships became more realistic. Being more in tune to our own standpoints as professor, graduate student, teacher, or artist allowed us to be more open to our limitations and strengths. Our collaboration deepened and became more efficient as we worked with our differences instead of against them. In this case, the praxis of digital storytelling democratized our own collaborative research process and teaching strategies.

In terms of thinking and doing applied anthropology, the digital storytelling process also led us to reflect about applied research in anthropology. Similar to the experiences of the high school youth, as researchers, it was initially hard to pay attention to the emotions involved in the digital storytelling process as important to our scholarly questions about media and pedagogy. This does not mean that we were unresponsive or dismissive of the youth's emotional responses. However, it was hard to place the youth's emotional reactions at the center of our inquiry and pedagogical 
practices. Our journey as applied researchers led us to take seriously the mutual and emotional relationships we developed with the youth and place them at the center of our research inquiry and pedagogical practice. The digital storytelling process helped remind us, as Sanjek suggests, of “...other values, brought from the wider social worlds in which we have grown up and in which we live as persons, actors, and citizens" (2015, p. 1). The social effects of digital storytelling drove us to think more deeply about our processes and to seek research opportunities in which we can learn from and work with youth. Because of this we committed almost a decade to IamWe and we strongly believe that long-term engagement in applied research is beneficial and necessary. To this end we continued to incorporate feedback from youth and they continued to inquire and participate in the IamWe activities even after they graduated from high school. Sustaining this kind of engagement is challenging. Justifying and making this kind of collaboration work across educational institutions is difficult. We battled with addressing logistical details related to differences in planning and scheduling. We struggled with having our work recognized as legitimate teaching and scholarship. We personally and professionally experienced the emotional weight that results from this committed praxis and mutuality (Sanjek, 2015). Yet, despite the challenges, these border crossings opened opportunities for anthropological research into new terrains of inquiry where digital media, personal emotional stories, and learning converge through mutual and transformative encounters experienced through the process of digital storytelling.

\section{References}

Benmayor, R. (2000). Education: Cyber-teaching in the oral history classroom. Oral History 28(1), 83-92.

Bernard, R. H. (2006). Research methods in anthropology: Qualitative and quantitative approaches. New York: Altamira Press.

Cammarota, J. (2008). The cultural organizing of youth ethnographers: Formalizing a praxis-based pedagogy. Anthropology \& Education Quarterly 39(1), 45-58.

Delgado Bernal, D., Elenes, C. A., Godinez, F. E., \& Villenas, S. (2006). Chicana/Latina education in everyday life: Feminista perspectives on pedagogy and epistemology. Albany: State University of New York Press.

Delgado Gaitan, C. (2005). Family narratives in multiple literacies. Anthropology \& Education Quarterly, 36(3), 265-272.

Fals Borda, O., \& Rahman, M. A. (1991). Action and knowledge: Breaking the monopoly with participatory action research. Lanham: Rowman \& Littlefield.

Freire, P. (2000). Pedagogy of the oppressed (30th anniversary ed.). New York: Continuum. (Original work published 1968)

Glaser, B. G., \& Strauss, A. L. (1967). The Discovery of grounded theory: Strategies for qualitative research. New York: Transaction Publishers; Reprint 2009.

Gubrium, A. (2009). Digital storytelling as method for engaged scholarship in anthropology. Practicing Anthropology, 31(4), 5-9. 
Heo, M. (2009). Digital storytelling: An empirical study of the impact of digital storytelling on pre-service teachers' self-efficacy and dispositions towards educational technology. Journal of Educational Multimedia and Hypermedia, 18(4), 405-428.

Kajder, S. B. (2004). Enter here: Personal narrative and digital storytelling. The English Journal, 93(3), 64-68.

Knight, M. G., Norton, N. E. L., \& Dixon, I. R. (2004). The power of black and Latina/o counterstories: Urban families and college-going processes. Anthropology \& Education Quarterly, 35(1), 99-120.

Lambert, J. (2013). Digital storytelling: Capturing lives, creating community. New York: Routledge.

McClaurin, I. (2001). Introduction: Forging a theory, politics, praxis and poetics of black feminist anthropology. In I. McClaurin (Ed.), Black feminist anthropology: Theory, politics, praxis and poetics (pp. 1-23). New Brunswick: Rutgers University Press.

McLellan, H. (2006). Digital storytelling in higher education. Journal of Computing in Higher Education, 19(1), 65-79.

Miller, L. C. (2010). Make me a story: Teaching writing through digital storytelling. Portland: Stenhouse Publisher.

Moll, L. C. (1992). Bilingual classroom studies and community analysis: Some recent trends. Educational Researcher, 21(2), 20-29.

Mukti, N. A., \& Hwa, S. P. (2004) Malaysian perspective: Designing interactive multimedia learning environment for moral values education. Educational Technology \& Society, 7(4), 143-152.

Nuñez-Janes, M. (2009) Historias digitales de estudiantes Latinos como herramienta pedagógica en Texas. In M. F. Montes \& W. Müllauer-Seichter (Eds.), La integración escolar a debate (pp. 56-79). Madrid: Pearson Educación, S.A.

Nuñez-Janes, M., \& Re Cruz, A. (2013). Latino/a students and the power of digital storytelling. Radical Pedagogy, 10(2). Retrieved from http://www.radicalpedagogy.org/radicalpedagogy. org/Latino_a_Students_and_the_Power_of_Digital_Storytelling.html

Ochs, E. (2007) Narrative lessons. In L. Monaghan \& J. E. Goodman (Eds.), A cultural approach to interpersonal communication (pp. 41-49). Malden, Ma: Wiley-Blackwell.

Olmedo, I. M. (1997). Voices of our past: Using oral history to explore funds of knowledge within a Puerto Rican family. Anthropology \& Education Quarterly, 28(4), 550-574.

Peer Assistance and Leadership (2014, October 31) Retrieved from http://www.statewidetraining. org/pal/

Robin, B. R. (2008). Digital storytelling: A powerful technology tool for the 21st century classroom. Theory Into Practice, 47(3), 220-228.

Sadik, A. (2008). Digital storytelling: A meaningful technology-integrated approach for engaged student learning. Educational Technology Research and Development, 56(4), 487-506.

Sanjek, R. (2015). Introduction. Deep grooves: Anthropology and mutuality. In R. Sanjek (Ed.), Mutuality: Anthropology's changing terms of engagement (pp. 1-10). Philadelphia: University of Pennsylvania Press.

Sheneman, L. (2010) Digital storytelling: How to get the best results. School Library Monthly, 27(1), 40-42.

Skouge, J. R., \& Rao, K. (2002) Digital storytelling in teacher education: Creating transformations through narrative. Educational Perspectives, 42(1), 54-60.

Spindler, G., \& Spindler, L. (1997). Cultural process and ethnography: An anthropological perspective. In G. Spindler \& L. Spindler (Eds.), Education and cultural process: Anthropological approaches (pp. 56-57). Long Grove: Waveland Press, Inc.

Wolf, D. L. (1996). Situating feminist dilemmas in fieldwork. In D. L. Wolf, (Ed.), Feminist dilemmas in fieldwork (pp. 1-56). Boulder, C0: Westview Press, Inc.

Yosso, T. (2006). Critical race counterstories along the Chicana/Chicano educational pipeline. New York: Routledge. 